\title{
Frozen chips: an unusual cause of severe frostbite injury
}

Colin A Graham, James Stevenson

\begin{abstract}
A case of severe frostbite injury to the right foot is presented. This was caused by the inappropriate application of a bag of frozen chips to the foot in an attempt to ease nonspecific pain. No specific acute traumatic injury was identified. As the patient was a teacher of physical education, the pain had initially been assumed to originate from a minor musculoskeletal injury. Full recovery ensued after surgical excision of necrotic tissue and split skin grafting. The danger of inappropriate overenthusiastic use of ice packs or other frozen material to treat soft tissue injuries is emphasised. The need for education to prevent similar future injuries is discussed.

(Br F Sports Med 2000;34:382-384)
\end{abstract}

Keywords: cold injury; frostbite; ice pack; skin; necrosis

A variety of unusual causes of frostbite in different anatomical locations have been described. ${ }^{1-7}$ They are often associated with sporting activities and exposure to extreme cold. Ice has long been used to ease the pain associated with acute musculoskeletal injuries and it continues to be recommended as a first aid measure in these circumstances. ${ }^{8}$ An unusual case of cold injury caused by application of a bag of frozen chips is described.

\section{Case report}

A 42 year old female physical education teacher presented to the accident and emergency department with an area of skin necrosis on the dorsum of her right foot. She gave a four week history of vague discomfort in her right foot with no known precipitating cause. Her symptoms had been partially relieved by oral non-steroidal antiinflammatory drugs prescribed by her general practitioner. Three days before presentation to the accident and emergency department, she had applied a bag of frozen chips wrapped in a towel to the dorsum of the foot in an attempt to relieve the discomfort. She fell asleep leaving the frozen chips in contact with the foot for at least $40 \mathrm{~min}$ utes. On awakening, the discomfort had resolved although she noticed erythema of the skin at the site of contact. The following day the dorsum of the foot became more discoloured and painful. She sought further advice from her doctor and was prescribed a course of flucloxacillin.
On the next day, she was referred by her doctor to the accident and emergency department with a swollen and painful foot. She complained of paraesthesia affecting the dorsum of the index and middle toes. There was a well demarcated 4 $\mathrm{cm} \times 3 \mathrm{~cm}$ area of full thickness skin necrosis on the dorsum of the foot surrounded by erythema and blistering (fig 1). Radiographs of the foot were normal. The clinical picture was consistent with full thickness skin necrosis secondary to frostbite ("third degree frostbite").

Initially the wound was dressed with paraffin tulle. On review eight days later, excision of the eschar and underlying necrotic fat was carried out under general anaesthesia. The necrotic tissue extended as deep as the extensor tendons, with destruction of the superficial cutaneous branches of the superficial and deep peroneal nerves to the index and middle toes. After a further 10 days the skin defect was covered with a split thickness skin graft. The wound then healed satisfactorily.

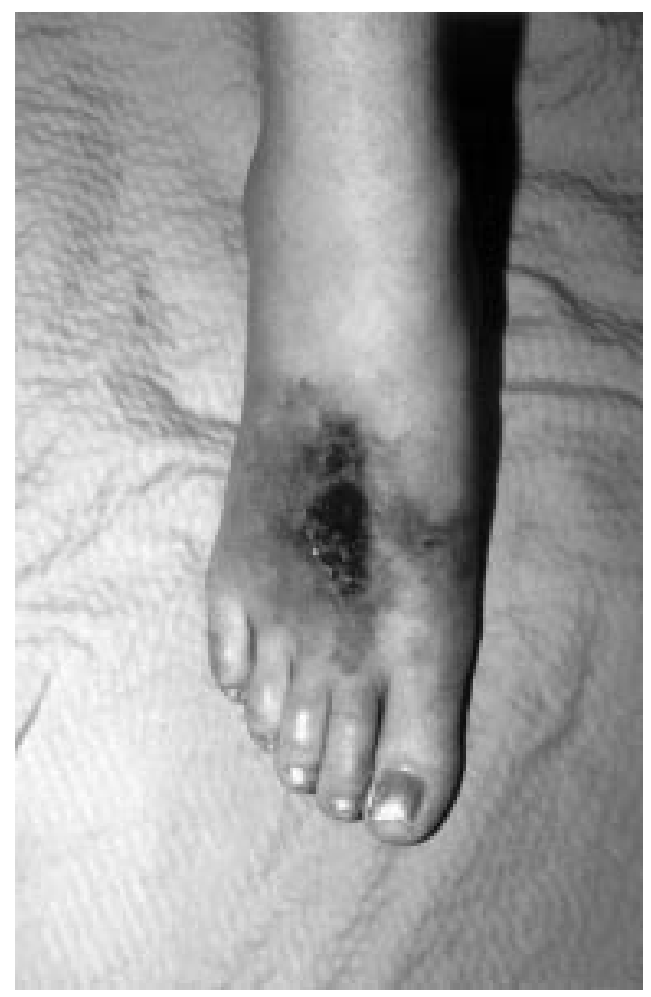

Figure 1 Cold injury on dorsum of right foot. 


\section{Discussion}

Severe full thickness cold induced injury is unusual. Most reported cases of frostbite involve superficial cold injury, which generally resolves spontaneously. ${ }^{13}$ Exposure to cold initially induces cutaneous anaesthesia, which probably contributed to the depth of cold injury sustained in this case. Anaesthesia is followed by the formation of intracellular ice crystals, which rapidly induce cell necrosis and tissue death. Endothelial injury exposes the vascular basement membrane, which causes sludging and aggregation of platelets; this is exacerbated by local vasoconstriction. ${ }^{9} 10$

Initial appearances in this case suggested deep dermal cold injury, "third degree" frostbite (fig 1). It was initially treated conservatively to allow demarcation of the wound and assessment of the depth of the injury. By the eighth day, the extent of tissue necrosis was evident and surgical excision was carried out.

The patient was aware that the application of ice was a useful way of relieving pain after acute soft tissue injury. It is clear that she was unaware of the dangers of prolonged application of ice. It has been recommended that ice or other "cold packs" should be wrapped in a towel, not allowed to come into direct contact with the skin, and not applied to the skin for more than 15 minutes at any one time. ${ }^{1}$

Although this injury is unusual, it is entirely preventable. Patient education could lessen the risk of this type of injury occurring in the future. Doctors and paramedical personnel in accident and emergency medicine, general practice, and sports medicine should be aware of the potential dangers of prolonged or inappropriate application of ice or similar frozen material. Patients must be reminded of the risks of cold treatment as well as the benefits.

1 Stevens DM, D'Angelo JV. Frostbite due to improper use of frozen gel pack. N Engl f Med 1978;299:1415.

2 Quist LH, Peltier G, Lundquist KJ. Frostbite of the eyelids following inappropriate application of ice compresses. Arch Ophthalmol 1996;114:226.

3 Travis S, Roberts D. Artic willy. BMF 1989;299:1573-4.

4 Myhre U, Goode PN, Miller IA. Jogger's phimosis. Br f Urol 1989;63:549.

5 Saxena A. Achilles peritendinosis: an unusual case due to frostbite in an elite athlete. F Foot Ankle Surg 1994;33:87-90. 6 Gamble WB, Bonnecarre ER. Coffee, tea or frostbite? A case report of inflight freezing hazard from dry ice. Aviat Space Environ Med 1996;67:880-1.

7 Moser S. Aerosol induced frostbite injury. $f$ Fam Pract 1999;48:666-7.

8 First aid manual: the authorised manual of St fohn Ambulance, St Andrew's Ambulance Association and The British Red Cross Society. 5th ed. London: Dorling Kindersley, 1987.

9 Washman B. Frostbite: what it is, how to prevent it, emergency treatment. $N$ Engl F Med 1962;266:974-89.

10 Vogel JE, Dellon AL. Frostbite injuries of the hand. Clin Plast Surg 1989;16:565-76.

Take home message

- Severe frostbite injury can result from inappropriate overenthusiastic application of ice or other frozen material

- Proper education is essential to prevent these injuries happening in the future

\section{Commentary}

This report again highlights the risks inherent in the application of a widely accepted and easily accessible modality which has recently been raised in this journal. ${ }^{1}$ It is difficult to find definitive recommendations in the literature on the frequency and duration of cold application, with few studies examining the effect of cold on blood flow over time. ${ }^{2}$ Ho et al found decreases in blood flow after five minutes of cold application, which were enhanced threefold to fourfold with applications up to 25 minutes. Most studies recommend application for between 20 and 30 minutes. . $^{3-5}$ However, case reports indicate a risk of nerve damage if the application is prolonged or over superficial nerve roots, or in athletes with little subcutaneous fat. ${ }^{6-8}$ It appears that, in the previously reported case, ${ }^{1}$ the weight of the limb on the ice pack with no intervening material may have compromised circulation beyond safe limits, and, in the present report, the prolonged application (>40 minutes) coupled with the weight of the frozen chips had the same effect.

The Association of Chartered Physiotherapists in Sports Medicine recently published guidelines on the application of PRICE for soft tissue injuries, ${ }^{9}$ which provide the following recommendations.

(1) The most effective duration of application is 20-30 minutes, with a maximum safe period of 30 minutes.

(2) A damp towel should be placed between the cooling agent and the skin.

(3) Care should be taken with the application of ice (or cooling agent) on areas with little subcutaneous fat or muscle, and in the region of superficial nerves, with a maximum cooling period of 10 minutes.

KATE KERR

University of Nottingham

1 O'Toole G, Ryatt S. Frostbite at the gym: a case report of an ice pack burn. Br f Sports Med 1999;33:278-9.

2 Ho SSW, Illgen RL, Meyer RW, et al. Comparison of various icing times in decreasing bone metabolism and blood flow in the knee. Am f Sports Med 1994;23:74-6.

3 McMaster WC, Liddle S, Waugh TR. Laboratory investigation of various cold therapy modalities. Am $\mathcal{f}$ Sports Med tion of various

4 Knight KL, Londeree BR. Comparison of blood flow in the ankle of uninjured subjects during therapeutic applications of heat, cold and exercise. Med Sci Sport Exerc 1980;12:76-80

5 Knight KL. Cryotherapy in sports injury management. International Perspectives in Physiotherapy 1980;4:163-5.
6 Covington DB, Bassett FH. When cryotherapy injures. Physician and Sports Medicine 1993;21:78-93.

7 Basset FH, Kirkpatrick JS, Englehardt DL, et al. Cryotherapy-induced nerve injury. Am f Sports Med 20: 516-18.

8 Green GA, Zachazewski JE, Jordan SE. Peroneal nerve palsy induced by cryotherapy. Physician and Sports Medicine 1989;17:63-70.

9 Kerr KM, Daley L, Booth L, et al. Guidelines for the management of soft tissue (musculoskeletal) injury with Protection, Rest, Ice, Compression and Elevation (PRICE) during the first 72 hours. London: Chartered Society of Physiotherapy, 1999. 